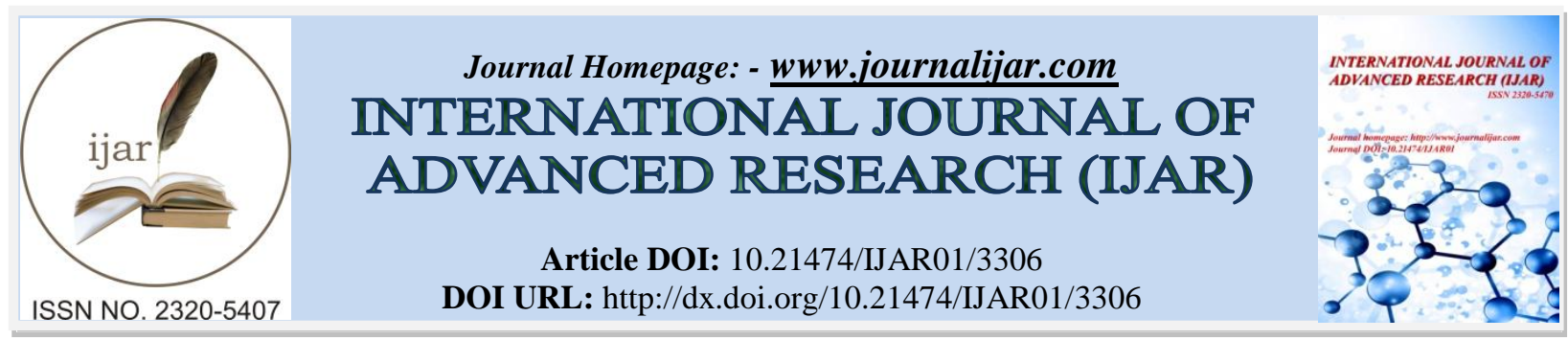

RESEARCH ARTICLE

\title{
ANALYSIS OF STRESS ON TWO POSTS WITH DIFFERENT LUTING SYSTEMS - THREE DIMENSIONAL FINITE ELEMENT STUDY.
}

Lakshmi tejaswi kancharana ${ }^{1}$, kaleswara rao atluri ${ }^{2}$, sunil chandra tripuraneni ${ }^{3}$, hemchand surapaneni ${ }^{3}$,

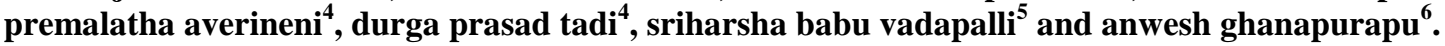

1. Post graduate student, dept of prosthodontics, drs sudha \& nageswararao siddartha institute of dental sciences, chinnoutapalli.

2. Professor and hod, dept of prosthodontics,drs sudha \& nageswararao siddartha institute of dental sciences, chinnoutapalli.

3. Professor, dept of prosthodontics,drs sudha \& nageswararao siddartha institute of dental sciences, chinnoutapalli.

4. Reader, dept of prosthodontics,drs sudha \& nageswararao siddartha institute of dental sciences, chinnoutapalli.

5. Senior lecturer, dept of prosthodontics,drs sudha \& nageswararao siddartha institute of dental sciences, chinnoutapalli.

6. Consultant endodontist.

\section{Manuscript Info}

.........................

Manuscript History

Received: 20 December 2016

Final Accepted: 05 January 2017

Published: February 2017

Key words:-

Ceramic Post, Glass Fibre Post, Luting

Cements, Stress.

\section{Abstract}

Aim:. The aim of this study was to investigate, by means of threedimensional finite element analyses (3D-FEA), the influence of post materials and luting cements on stress distribution within posts, root dentin and their displacement under $100 \mathrm{~N}$ identical perpendicular loading,

Materials and Methods: A $3 \mathrm{~mm}$ section of endodontically treated canine tooth was scanned and reconstructed for 3-D modelling and Finite Element analysis(FEA). A ceramic post (CP) and a glass fibre post (GFP) were tested individually with four luting cements zinc phosphate (ZPH), glass ionomer (GI), resin modified glass ionomer (RMGI) and resin based cements (RC). A push-out test was conducted by subjecting all models to $100 \mathrm{~N}$ perpendicular loading at the post.

Results: The maximum stresses generated along the CP-cement interface were significantly higher than corresponding stresses in the GFP-cement interface regardless of the cement type. GFP generated seven times higher stresses within theroot dentine than metal posts when ZPH and GI were used, and three times higher when RMGI and RC were used. The displacement of GFP was double $(20 \mu)$ the displacement of $\mathrm{CP}(50 \mu)$ in all groups.

Conclusions: The low elastic modulus of GFP generated lower stresses along its interface and higher stresses within the root dentine, therefore the probability of debonding and root fracture in the GFP group was lower. 


\begin{abstract}
Abbreviations and acronyms:-
FEA = finite element analysis; GFP = glass fibre post; GI = glass ionomer; $\mathrm{CP}=$ ceramic post;PDL $=$ periodontal ligament; $\mathrm{RC}=$ resin based cements; $\mathrm{RMGI}=$ resin modified glass ionomer; $\mathrm{ZPH}=$ zinc phosphate.
\end{abstract}

\title{
Introduction:-
}

The criteria for the use of a cast metal, metal ceramic or all ceramic restoration of a tooth that has been damaged to the extent that it must be reinforced or protected to withstand the masticatory load without fracture. Most individual teeth requiring cemented restorations, as well as many fixed partial denture abutments, have been damaged enough to require modification of classic preparation design. The amount of tooth structure destroyed is only one factor to consider in selecting a restorative material and designing a preparation.

Endodontically treated teeth usually undergo several changes due to loss of blood supply, dehydration, alteration of the physical and mechanical properties of the tooth, let alone the loss of significant sound tooth tissues. Subsequently endodontically treated teeth become susceptible to crack or fracture especially when posts are considered for restoring these teeth. ${ }^{1}$

Restoration of endodontically treated teeth is a common problem in restorative dentistry, related to the fractures occurring in such teeth. Endodontically treated teeth are affected by a higher risk of biomechanical failure than vital teeth. The access preparation for endodontic treatment causes the loss of the roof of the pulp chamber, which may account for the relatively high fracture incidence documented in pulpless teeth. ${ }^{2}$

The clinical decision as to whether to restore an endodontically treated tooth by provision of an intracoronal or extracoronal restoration is empirical. When the endodontically treated tooth is left with limited supraosseous tissues, a post might be considered for their restoration to provide a platform for retention, either for an intracoronal or extracoronalrestoration.Various in vitro and in vivo research advocated improved root fracture resistance, the reported success rate for post and core restorations was $83-97 \% .^{1}$

On the contrary, post-induced stresses within root dentine, particularly in debonded posts, are the main factors in initiating crack formation which might lead to root fracture. Some studies suggested that a post should only be considered when there is insufficient coronal remaining tissue to retain the core and support the definitive restoration.

Fibre reinforced posts have several advantages over other posts owing to their elastic modulus which is similar root dentine and bonding potential when resin based luting cements are considered. The clinical performance of fibre posts and direct composite full cuspal coverage was comparable to indirect metal crowns over a period of three years in clinical service.

The ultimate aim of bonding fibre reinforced composite post is to create a monoblock within the root canal system, as the elastic modulus being similar to root dentine, in order to improve the root fracture resistance and reduce the problems associated with debonding of fibre posts.

The purpose of this study was to investigate, by means of three-dimensional finite element analyses (3D-FEA), the influence of post materials and luting cements on stress distribution within posts and root dentine, and their displacement under $100 \mathrm{~N}$ identical perpendicular loading.

The hypothesis to be tested in this study was that no difference exists between ceramic posts and glass fibre posts cemented with different luting cements in terms of their stress generation and the risk of root fracture under occlusal loading.

\section{Materials and method:-}

An endodontically treated canine root was scanned using micro computed tomography. Scans were imported by for segmentation and masking depending on pixel density. Subsequently, a 3-D model was developed to represent a post (ceramic or glass fibre), cement, root dentine, periodontal ligament (PDL) and alveolar bone(Figure 1-7). Four luting cements [zinc phosphate $(\mathrm{ZPH})$, glass ionomer $(\mathrm{GI})$, resin modified glass ionomer (RMGI) and resin based cements (RC)] were employed and divided into two groups: Ceramic post $(\mathrm{MP})(\mathrm{n}=4)$ and glass fibre post $(\mathrm{GFP})(\mathrm{n}$ 
= 4) groups. Finite element $(\mathrm{FE})$ meshing was carried out by AnsysPreprocessor to create eight FE models, each of which was $3 \mathrm{~mm}$ thick; within these eight models the thickness of PDL and cement was identical $(0.2 \mathrm{~mm})($ Figure 7,8).

Care was taken to concentrate elements in the region of greatest interest of stress distribution pattern. The element was defined as 10 nodes having degrees of freedom at each node; the elements were constructed so that their size aspect ratio would yield accuracy. elastic modulus and coefficient of poisson which were obtained from the literature. The FE model comprises 20165nodes and 15904 hexahedral elements, and the aspect ratio throughout the model was close to 1:1. All the vital tissues (cortical bone,PDL, dentin), ceramic post, and four luting cements zinc phosphate (ZPH), glass ionomer (GI), resin modified glass ionomer (RMGI) and resin based cements (RC) except glass fibre post (GFP) were presumed to be linearly elastic, homogenous and isotropic. Glass fibre post (GPF) was considered orthotropic.

The corresponding elastic properties such as young's modulus and Poisson's ratio of bone, periodontal ligament, dentin, luting cements, ceramic post and glass fibre post were determined using literature survey(Table 1).

All eight models with ceramic and glass fibre post and four luting cements were used for load application and load analysis. A $100 \mathrm{~N}$ push out force was applied vertically to calculate the stresses in root dentin, post and luting cement and the amount of displacement induced.

These different models were analyzed by the processor and displayed by post processor of the finite element software (Ansys, version 8.0) using von mises stresses analysis. Von mises stress values are defined as the beginning of deformation for ductile materials. Failure occurs when von mises stress values exceed the yield strength of a material. ${ }^{3}$

\section{Results:-}

The study is done using three-dimensional finite element analyses (3D-FEA), to study the influence of post materials and luting cements on stress distribution within posts and root dentine, and their displacement under $100 \mathrm{~N}$ identical perpendicular loading.

Table 2 and Table 3 show the comparative values of principal stress, post stress, dentin stress, cement stress and deformation with ceramic and glass fibre post.

Figure 4-8 show the comparative values of stress distribution among the four luting agents [ zinc phosphate, GIC, RGIC, RC]

\section{Discussion:-}

Post and core systems are commonly used for the restoration of endodontically treated teeth when the teeth have suffered coronal damage. Loosening of the post and core or fracture of remaining dentin root are most frequent problems observed.

Several methods have been used to analyze the effects of the post-core system on the stress distributions in dentin. Experimental methods and the finite element method are commonly used. Experimental methods include tensile test, shear loading test, and photoelastic analysis. Photoelasticity is based on the property of some transparent materials to exhibit colorful patterns when viewed with polarized light.

In the two dimensional (2D) method, models are fabricated using a transparent plastic sheet. However, 2D finite element models are regarded as inadequate since the tooth structure and the loading forces are not two-dimensional. A 3D finite element method is a more accurate way to analyze the stresses in a tooth using ANSYS software. The finite element method has been used for more than two decades for stress analysis of teeth. ${ }^{4-8}$

All mechanical properties are measures of the resistance of a material to deformation, crack growth, or fracture under an applied force or pressure and the induced stress. An important factor in the design of a dental prosthesis is strength, a mechanical property of a material, which ensures that the prosthesis serves its intended functions effectively and safely over extended periods of time. 
In this 3-D FEA study, a section of the upper canine root was from segmented micro CT data to create a sophisticated model which was subjected to a push-out pressure at the post area to estimate post displacement and stress distribution in different cement types and post materials.100N Push Out Test was performed and the Stress Distribution was studied along ceramic post $(\mathrm{P} 1)$, glass fibre post $(\mathrm{P} 2)$ and four luting agents; zinc phosphate, glass ionomer, resin modified GIC, resin cement [TABLE 2,3]

The stresses generated in ceramic post using four luting agents were (23.782Mpa, 23.849Mpa, 22.268Mpa, 23.269Mpa) respectively which were uniform

Post and core systems are commonly used for the restoration of endodontically treated teeth when the teeth have suffered coronal damage. Loosening of the post and core or fracture of remaining dentin root are most frequent problems observed.

The stresses generated in glass fibre post using four luting agents were (18.256Mpa, 18.266Mpa, 18.405Mpa, $18.341 \mathrm{Mpa}$ ) which were uniform among four cements. The stresses generated were more in ceramic post than the glass fibre post irrespective of the luting agents.

The stresses generated in ceramic post are less when RMIC was used (22.268Mpa) and more when ZP was used (23.782Mpa) when four luting cements were used. The stresses generated in Glass fibre post are less when RC was used (16.554Mpa) and more when GIC was used (17.318Mpa) when four luting cements were used.

The stresses generated among cement interface was less when glass fibre post was used with RC (12.529Mpa) and more when ceramic post was used with ZP (20.673Mpa).

The stresses generated within dentin were less when glass fibre post was used with RC (9.369Mpa) and more when ceramic post was used with RC (16.425Mpa.)

The deformation of the post was less when glass fibre post is used with $\mathrm{RC}(0.02 \mathrm{~mm})$ and more when ceramic post was used with RMIC $(0.05 \mathrm{~mm})$.

The elastic modulus of fibre posts which is lower than the ceramic post and similar to root dentine generated lower stresses along the post-cement interface compared with ceramic posts. The stresses generated within the root dentine were much less in the Glass fibre post groups as the elastic modulus of glass fibre post is similar to dentin.

The findings of this study are in agreement with another recent 3-D FEA study which indicated that stress within root dentine is lower in the GFP group than their counterparts, the risk of root fracture is lower in the fibre post group. ${ }^{9-10}$

Root cracks are usually initiated after posts debonding takes place; the level of induced stresses will be dramatically increased and become concentrated at the small surface area of the root dentine. When these concentrated stresses exceed the tensile strength tensile strength of root dentine, it will subsequently result in a clinically or radiographically detectable root fracture. ${ }^{11,12}$

Creating a monoblock within the root canal system with post having similar modulus of elasticity to root dentin is a key for long-term survival of posts.Therefore, fibre posts bonded to root dentine with dual-cure bonding resin cement is a prerequisite for a durable restoration. ${ }^{13}$

Glass ionomer and resin modified glass ionomer cements have bonding potential to root dentine, lower solubility, higher tensile strength and fluoride release. However, they suffer some limitations like solubility and microleakage which makes them susceptible to hydration and expansion, and subsequently debonding and failure of the whole restoration. $^{14}$

Resin based luting cements are most widely used in bonding posts to root dentine. However, some studies have cast doubt on their bonding strength to root dentine and indicated that degradation and disintegration might happen over time. Subsequently, this might lead to microleakage along the dentine-cement interface. ${ }^{15-16}$

Conversely, other reports indicate resin based cements improve fracture resistance of endodontically treated teeth and reduce microleakage compared to other cements. In light of the findings of this study, it has been demonstrated 
that resin cement along with fibre posts reduce, to a great extent, the stress along the root-cement interface and post displacement and subsequently root fracture which was in agreement with another push-out FEA study. ${ }^{17}$

\section{Summary:-}

Post-core restored endodontically treated teeth are complex systems due to the small dimensions, structural complexities, multiple components with significantly different material properties, and variations in loading directions and the magnitudes. A 3D finite element model has been developed, which includes dentin, PDL, bone, post and luting agent. Because of their elastic modulus being similar to dentin, the cementum is included in the dentin portion of the tooth. All components have been assumed to be perfectly bonded, and all materials have been assumed to be homogenous, isotropic, linear and elastic.

The geometrical model has been built using Pro/Engineer and the commercial finite element analysis package ANSYS has been used for the generation of the finite element model, stress calculations and post processing. A convergence test has been conducted to determine the proper number of the elements. Principal stresses in dentin, posts, luting agent and the deformation have been calculated, and the results have been shown in graphic forms.

\section{Conclusion:-}

Within the limitations of this FEA ANSYS software study, the following conclusions were made;

1. A post with high elastic modulus causes high stress concentrations in dentin and the posts.

2. The stress distributions in both dentin, post and cement interface were high in ceramic post when compared with glass fibre post.

3. Deformation of the post is more in ceramic post $(50 \mu)$ when compared to glass fibre post $(20 \mu)$.

4. Among the luting agents resin cement and resin modified GIC showed lower stress concentrations when used with ceramic and glass fibre post.

5. High stresses in dentin are highly undesirable because they may cause the fracture of dentin and failure of the restored

tooth.

\section{Acknowledgement:-}

I take this privilege \& pleasure to acknowledge the contributions of many individuals who have been inspirational \& supportive throughout my work undertaken \& endowed with the precious knowledge to see success in my endeavor. It is my privilege and honour to express my most sincere and heartfelt thanks to Dr.KALESWARA RAO ATLURI, Professor \& H.O.D, Department of Prosthodontics and crown \& bridge, Drs.Sudha\&Nageswara Rao Siddhartha Institute of Dental Sciences for his valuable guidance, keen interest, perennial inspiration \& everlasting encouragement. I shall forever remain indebted to him for having inculcated in me a quest for excellence, a spirit of diligence \& perseverance, a sense of humility, honesty \& respect for the moral \& ethics which govern our sciences $\&$ without whom this work would not have seen the light of the day.

I would like to thankDr. V. RAVI KIRAN, Professor,Dr. T. SUNIL CHANDRA, Reader, Dr. S. HEMCHAND, Reader, Dr. A. PREMALATHA, Reader, Dr. T. DURGA PRASAD, Reader, Dr. V. HARSHA, Senior Lecturer for their valuable guidance, constant encouragement and suggestions throughout the study.

I am thankful to Dr. M. V. RAMOJI RAO, Principal for permitting me to utilize the facilities required for the study.

I would like to thank M. NAGABHUSHAN, FEA software analyzer who helped me to complete my study through his skill and support.

I thank my batchmatesDr. Y. TEJASWI and Dr. K. DURGA BHAVANIfor their support and encouragement. I also thank my juniors Dr. P. PAVANI, Dr.CH. DEEPIKA, Dr. P. ANISH, Dr. K. SRIVANI, Dr. K. SUSHMA and Dr. CH. TEJASWIfor assistance during my study and also for their love and moral support. 


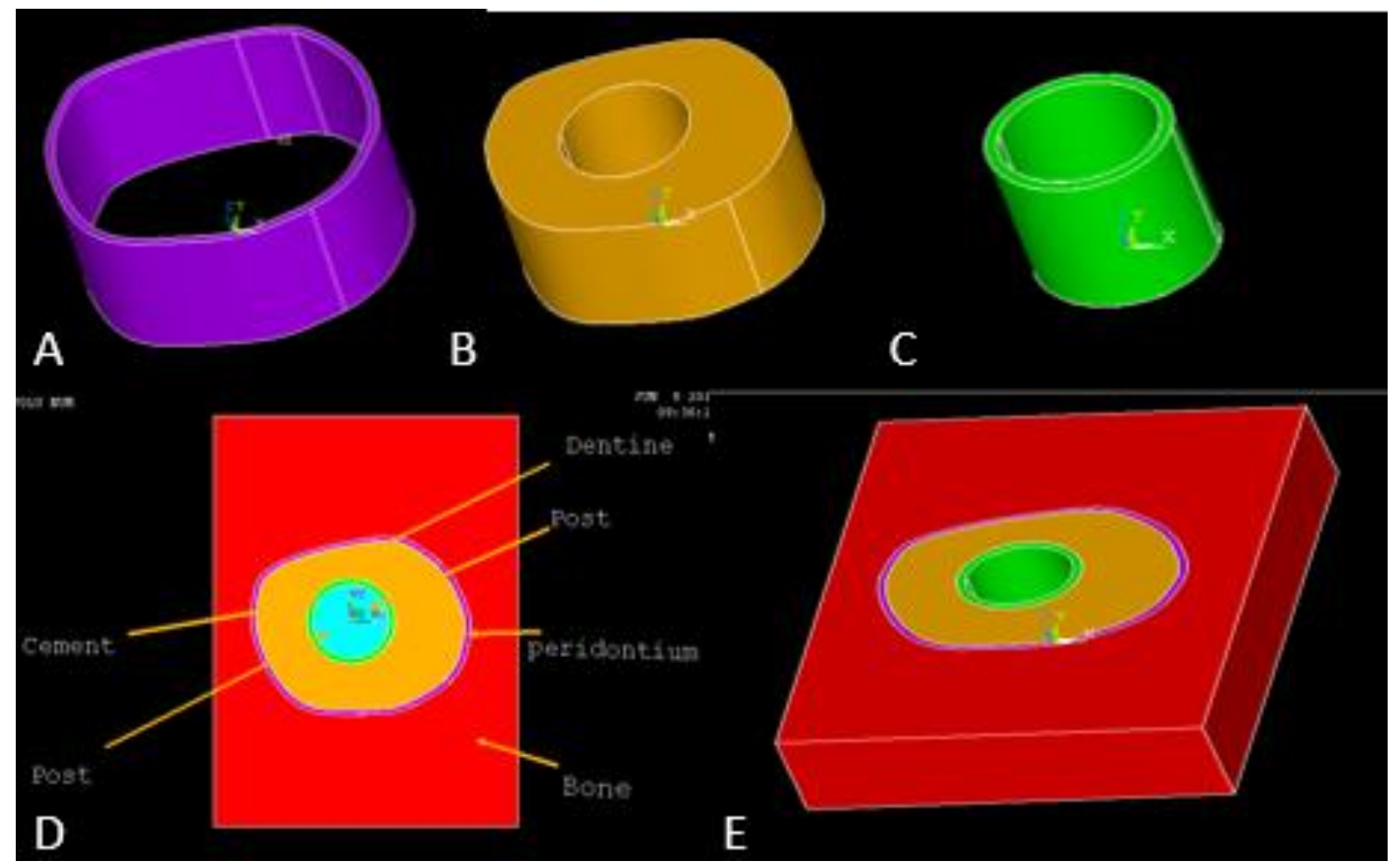

Figure 1:- Fea Model Of A,Periodontal Ligament; B.Dentin; C.Luting Agent; D.Post; E.Without Post

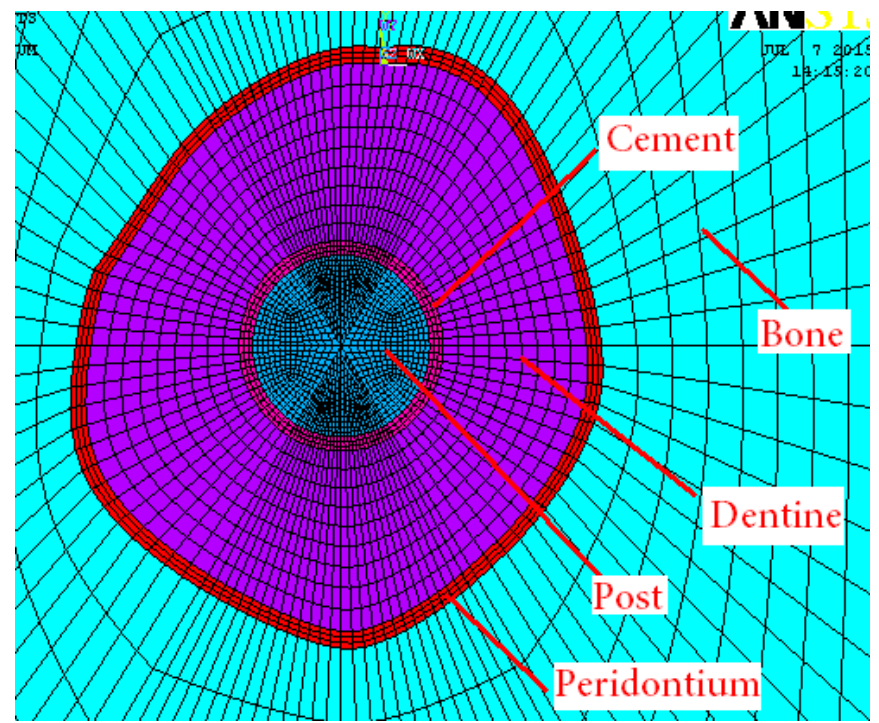

FIGURE 2: Mesh Plot 


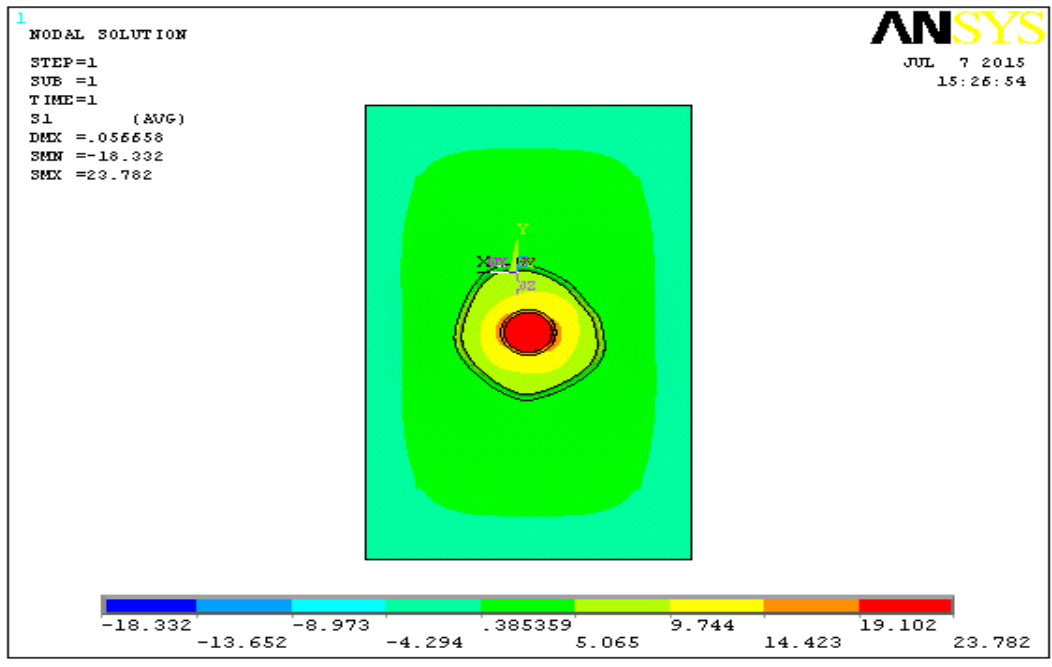

FIGURE 3: Overall Stress

Table 1:-

\begin{tabular}{|l|l|l|}
\hline & Elastic modulus (Mpa) & Poisson's ratio \\
\hline Zinc phosphate & 22400 & 0.25 \\
\hline Glass ionomer & 16900 & 0.30 \\
\hline RMIC & 4000 & 0.30 \\
\hline Resin cement & 7000 & 0.27 \\
\hline Dentine & 18600 & 0.31 \\
\hline PDL & 69 & 0.45 \\
\hline Bone & 14000 & 0.15 \\
\hline Ceramic post & 69000 & 0.28 \\
\hline Glass fibre post & 37000 & 0.27 \\
\hline
\end{tabular}

\begin{tabular}{|l|l|l|l|l|}
\hline & \multicolumn{4}{l}{ POST 1 } \\
\cline { 2 - 5 } & CEMENT 1 & CEMENT 2 & CEMENT 3 & CEMENT 4 \\
\hline DEFORMATION & 0.0566 & 0.0567 & 0.0577 & 0.0572 \\
\hline PRINCIPAL STRESS & 23.782 & 23.849 & 22.268 & 23.269 \\
\hline POST STRESS & 23.782 & 23.849 & 22.268 & 23.269 \\
\hline CEMENT STRESS & 20.673 & 20.409 & 17.658 & 19.024 \\
\hline DENTIN STRESS & 16.035 & 16.025 & 15.678 & 16.425 \\
\hline
\end{tabular}

TABLE 2:- Comparative values of principal stress, post stress, dentin stress, cement stress and deformation with

\begin{tabular}{|c|c|c|c|c|}
\hline \multicolumn{5}{|c|}{ ceramic post } \\
\hline & CEMENT 1 & CEMENT 2 & CEMENT 3 & CEMENT 4 \\
\hline DEFORMATION & 0.0202 & 0.0204 & 0.0208 & 0.0201 \\
\hline PRINCIPAL STRESS & 18.256 & 18.266 & 18.405 & 18.341 \\
\hline POST STRESS & 17.151 & 17.318 & 17.078 & 16.554 \\
\hline CEMENT STRESS & 14.262 & 14.07 & 13.339 & 12.529 \\
\hline DENTIN STRESS & 10.643 & 10.341 & 10.79 & 9.369 \\
\hline
\end{tabular}

TABLE 3:- Comparative values of principal stress, post stress, dentin stress, cement stress and deformation with glass fibre post 


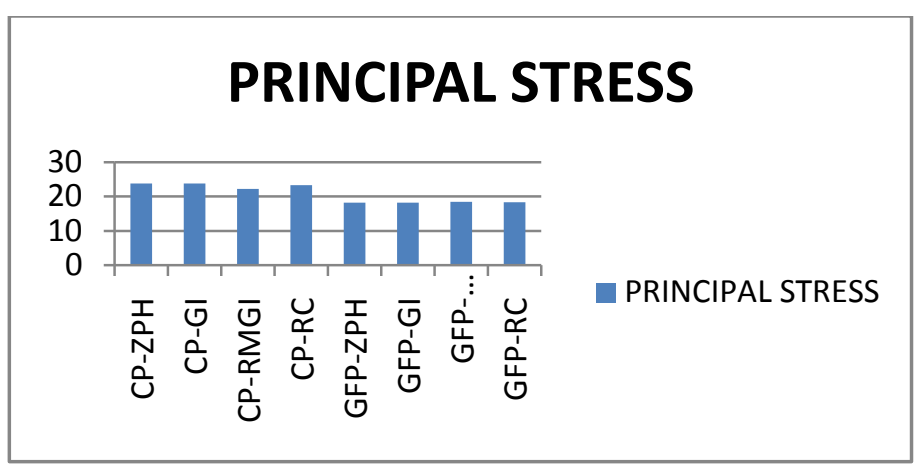

Figure 4

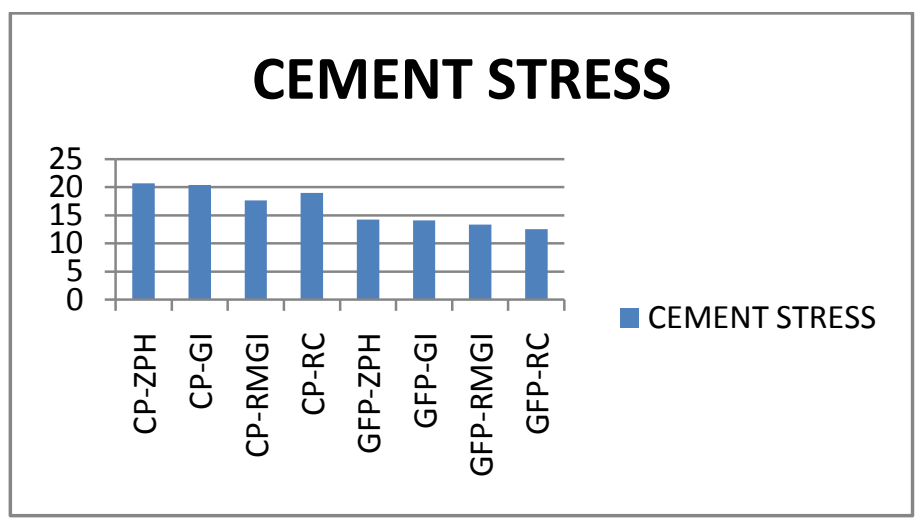

Figure 5

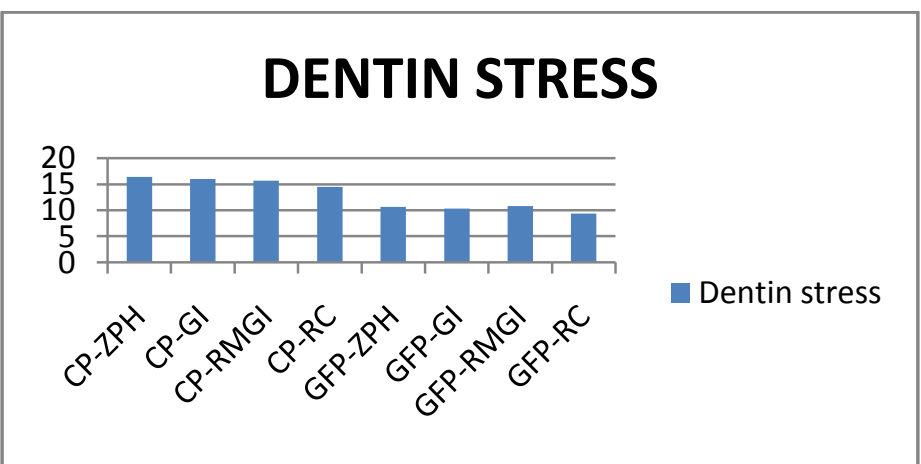

Figure 6

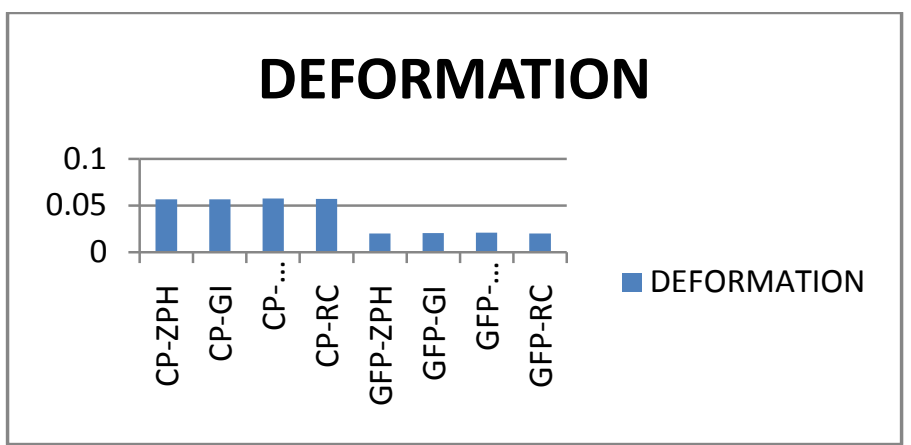

Figure 7 


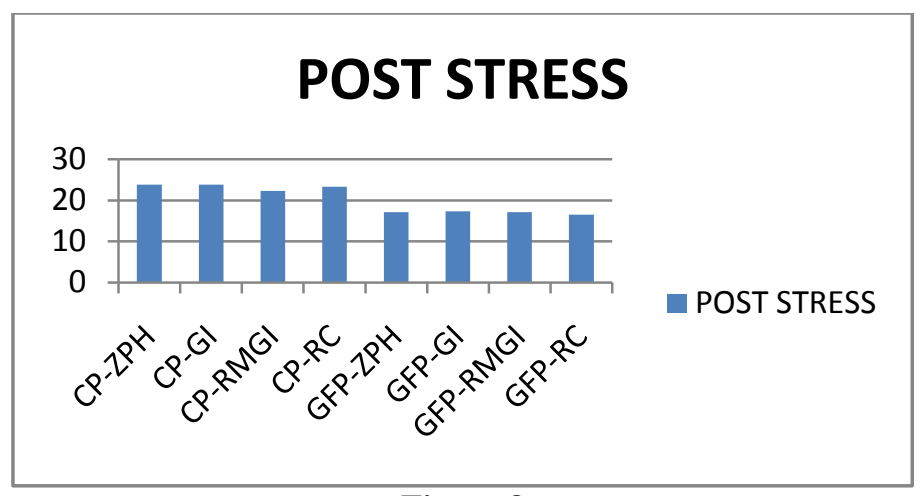

Figure 8

\section{Refernces:-}

1. SA Romeed, SM Dunne. Stress analysis of different post-luting systems: a three-dimensional finite element analysis. Australian Dental Journal 2013;58:82-88.

2. Fernando Zarone, Roberto Sorrentino, DavideApicella, Bartolomeo Valentino, Marco Ferrari, R. Aversa, A. Apicella. Evaluation of the biomechanical behavior of maxillary central incisors restored by means of endocrowns compared to a natural tooth: A 3D static linear finite elements analysis. Dental materials 2006;22:1035-44.

3. ShindeHarshada H. Finite Element Analysis: Basics And Its Applications In Dentistry. Indian Journal of Dental Sciences. March 2012;1:4.

4. Ho M.H, Lee, S. Chen, H. and Lee, M., Three-dimensional finite element analysis of the effects of posts on stress distribution in dentin, Journal of Prosthetic Dentistry1994;72:367-72.

5. Toparli, M., Gokay, N. and Aksoy, T. An investigation of the stress values on a tooth restored by amalgam, Journal of Oral Rehabilitation 1999;26:259-63.

6. Rubin, C., Krishnamurthy, N., Capilouto, E. and Yi, H., Stress analysis of the human tooth using a threedimensional finite element model, Journal Dental Research 1983;62:82-86.

7. Ko, C.C., Chu, C.S., Chung, K.H. and Lee, M.C., Effects of posts on dentin stress distribution in pulpless teeth, Journal of Prosthetic Dentistry 1992;68:421-27.

8. Toparli, M., Gokay, N. and Aksoy, T. Analysis of a restored maxillary second premolar tooth by using threedimensional finite element method, Journal of Oral Rehabilitation 2000;26:157-64.

9. A.F.V. Santos, J.B.C. Meira,C.B. Tanaka1, T.A. Xavier,R.Y. Ballester, R.G. Lima,C.S. Pfeifer and A.Versluis .Can Fiber Posts decrease Root Stresses and Reduce Fracture? J Dent Res 2010;89(6):587-91.

10. Miguel Gómez-Polo, Blanca Llido, Antonia Rivero, Jaime del Rı'o, Alicia Celemı'n. A 10-year retrospective study of the survival rate of teeth restored with metal prefabricated posts versus cast metal posts and cores. Journal of dentistry 2010;38:916-20.

11. Michael Naumann, Guido Sterzenbac, Martin Rosentritt,FlorianBeuer,and Roland Frankenberger. Is Adhesive Cementation of Endodontic Posts Necessary?JEndod 2008;34:1006 -10.

12. N. Wakabayashi, M. Ona, T. Suzuki,Y. Igarashi. Nonlinear finite element analyses: Advances and challenges in dental applications. Journal of dentistry 2008;36:463-71.

13. Bitter K, Neumann K, Kielbassa AM. Effects of pretreatment and thermocycling on bond strength of resin core materials to various fiber-reinforced composite posts. J Adhes Dent 2008;10:481-89.

14. Kiyoshi Tajima, Ker-Kong Chen, Nobusuke Takahashi, Naoaki Noda, Yuki NagamatsuAnd Hiroshi Kakigawa. Three-dimensional finite element modeling from CT images of tooth and its validation. Dental Materials Journal 2009; 28(2):219-26.

15. J. Sindel, R. Frankenberger, N. Kramer, A. Petschelt.Crack formation of all-ceramic crowns dependent on different corebuild-up and luting materials. Journal of Dentistry 1999;27:175-81.

16. Carlos J. Soaresa, Fernanda R. Santanaa, Carolina G. Castroa, Paulo C.F. Santos-Filhoa,Paulo V. Soaresa, Fang Qianb, Steven R. Armstrong. Finite element analysis and bond strength of a glass post to intraradicular dentin: Comparison between microtensile and push-out tests. Dental materials 2008;24;1405-11.

17. Scianamblo M. Restorations and endodontic success: The correlationship of post-endodontic restorations and endodontic success: rationale and materials. EndodPract 2002:29-39 